\title{
PERCEPÇÕES DE ESTUDANTES E EGRESSOS DO ENSINO MÉDIO SOBRE O CURSO DE CIÊNCIAS CONTÁBEIS: UMA ANÁLISE SOB A ÓTICA DOS ESTEREÓTIPOS DA PROFISSÃO
}

\author{
High School student's perceptions in relation to the Accounting: An \\ analysis of the stereotypes of profession
}

Jucellia Paulista de Almeida

E-mail: jucellia.almeida@gmail.com

Bacharel em Ciências Contábeis pela Universidade Federal de Minas Gerais.

https://orcid.org/0000-0002-9285-2133

Bruna Camargos Avelino

E-mail: bcavelino@gmail.com

Doutora em Controladoria e Contabilidade pela Faculdade de Economia, Administração, Contabilidade e Atuária da Universidade de São Paulo; Mestra em Ciências Contábeis pela Universidade Federal de Minas Gerais; Professora Adjunta no Departamento de Ciências Contábeis da Universidade Federal de Minas Gerais.

Endereço para contato: Avenida Pres. Antônio Carlos, 6627, Pampulha, 31270-901, Belo Horizonte, Minas Gerais, Brasil. https://orcid.org/0000-0001-8958-8725

Talles Vianna Brugni E-mail: tallesbrugni@hotmail.com

Pós-doutor em Finanças pela Pontifícia Universidade Católica do Rio de Janeiro; Doutor em Controadoria e Contabilidade pela Universidade de São Paulo; Professor Associado na Fucape Business School. https://orcid.org/0000-0002-9025-9440 


\section{Resumo}

Este estudo teve o objetivo de conhecer e analisar as percepções de estudantes e egressos do Ensino Médio com relação à Graduação em Ciências Contábeis sob a ótica de estereótipos associados à profissão. O estudo ocorreu mediante a aplicação de questionários aos indivíduos componentes da amostra, presentes no evento Mostra de Profissões/Mostra Sua UFMG, promovido pela Universidade Federal de Minas Gerais (UFMG), e em um cursinho preparatório de vestibular localizado no Município de Lagoa Santa, região metropolitana de Belo Horizonte, Minas Gerais. Além disso, o questionário também foi disponibilizado on-line na plataforma do Google Drive. A partir da análise dos dados, realizada por meio da construção de tabelas e análises de frequência, constatou-se um desconhecimento dos respondentes sobre vários aspectos inerentes ao Curso e à profissão contábil. No que diz respeito aos estereótipos apontados na literatura, este trabalho não encontrou outro senão aquele que relaciona a Contabilidade à Ciência Exata, e uma parcela considerável dos indivíduos ainda vincula a principal tarefa do Contador ao cálculo do imposto de renda. Ressalta-se, desse modo, a necessidade de as escolas que possuem o Ensino Médio fornecerem informações adequadas a respeito das carreiras pretendidas pelos alunos, bem como estimularem a participação destes em eventos como a Mostra de Profissões realizada pela UFMG.

Palavras-chave: Estereótipos. Ciências Contábeis. Estudantes.

\section{Abstract}

This study aimed to know and analyses the High School student's perceptions-in progress or formed-in relation to the Accounting from the perspective of stereotypes associated to the profession. The study adopted for data collection a questionnaire applied to the sample component students present at the Professions Exhibition event at the Federal University of Minas Gerais (UFMG) and in a preparatory course located in Lagoa Santa, metropolitan region of Belo Horizonte, Minas Gerais. In addition, the questionnaire was also available online on Google Drive platform. Based on the analysis of the data, performed through the construction of tables and frequency analysis, there was a lack of knowledge of the respondents about several aspects inherent the Course and the accounting profession. About the stereotypes pointed in the literature, this work has found no other than that which relates Accounting to Exact Science and a considerable part of the students still links the main task of the Accountant to the income tax calculation. That is, the view of the accountant as paramount to the decision-making process in companies appears in the background. Thus, is necessary that High School institutions provide adequate information about the careers desired by the students, as well as stimulate the participation in events such as the Professions Exhibition conducted by UFMG.

Keywords: Stereotypes. Accounting. Students.

\section{INTRODUÇÃO}

A Contabilidade está presente no dia a dia dos indivíduos e apresenta um papel relevante para a sociedade: coletar dados e torná-los mais inteligíveis aos usuários da informação contábil. No entanto, Miranda, Miranda, e Araujo (2013) apontam que a profissão contábil tem baixa valorização quando comparada a carreiras mais tradicionais, como o 
Direito, a Medicina e a Engenharia, e as atividades do Contador não são consideradas atraentes.

Entende-se que a escolha da carreira a ser seguida por um estudante é pautada, entre diversos motivos, pelos seus gostos pessoais e percepções com relação ao curso escolhido. Segundo Baccega (1998), as percepções, por sua vez, são formadas por meio do processo de comunicação: as informações mais acessíveis são apropriadas primeiramente. Porém, é possível que essas informações mais acessíveis estejam carregadas de estereótipos que, em determinadas situações, diferem da realidade. Por conseguinte, o processo de escolha do curso poderá ser tendencioso, não retratando informações adequadas a respeito da profissão.

De acordo com o dicionário de língua portuguesa Dicionário Priberam da Língua Portuguesa (2013), o estereótipo é uma ideia ou conceito formado antecipadamente ou sem fundamento real e adaptação à situação presente. Nesse sentido, no que diz respeito à profissão contábil, observa-se uma série de estereótipos associados a ela. Vaivio e Kokko (2006), por exemplo, apontam a figura do "bean counter" ou "contador de feijão", isto é, uma pessoa metódica, conservadora, quantitativa e, sobretudo, chata. Além disso, os autores definem o Contador como um profissional que não possui entendimento ou sensação do negócio e desenvolve processos mecânicos e distantes da realidade, que sufocam a iniciativa e, possivelmente, levam a organização a tomar decisões prejudiciais a ela. Em estudos mais recentes, nota-se que a imagem do profissional contemporâneo ainda está vinculada, em alguns aspectos, à do Contador tradicional: o estudo de Leal, Miranda, Araújo, e Borges (2014) identificou que, na percepção pública, o estereótipo para o sexo masculino se mantém na profissão contábil. A pesquisa de Galvão (2016) retrata que os estudantes vinculam - Contador principalmente ao processo de cálculo de impostos. E os autores Rebellato, Nascimento, e Rodniski (2017) concluíram que o profissional contábil ainda é visto como um indivíduo focado na manutenção de registros, que resolve questões burocráticas e operacionais.

Adicionalmente, escândalos contábeis contribuem para tais estereótipos e para uma percepção negativa sobre o trabalho do profissional da Contabilidade. Um exemplo é a fraude contábil ocorrida na Enron: a empresa criou uma série de complexas transações financeiras que permitiram tratar empréstimos tomados como se fossem vendas efetuadas. Por fim, o lucro e a rentabilidade da Companhia foram inflados, e as dívidas, ocultas. Criaramse, então, dois problemas: o da fraude propriamente dita, em que os contadores mentiram nos balanços e o fato de a empresa de auditoria independente também ter sido solidária com a fraude (FGV On-line, 2019). Conforme Silva (2007), "O escândalo gerado no campo financeiro provocou uma discussão no congresso norte-americano e no mercado mundial sobre assuntos como ética, papel da informação contábil e credibilidade" (p. 11). 
Os estereótipos mencionados anteriormente corroboram a formação de um perfil do profissional e da profissão contábil de maneira negativa, de modo que as percepções e expectativas da sociedade poderão ser prejudiciais à profissão contábil. Azevedo e Cornachione (2012) mencionam que, se as pessoas vinculam a área da Contabilidade a práticas eticamente duvidosas ou, ainda, a ações desligadas de comprometimento social, estudantes que valorizam a ética e a responsabilidade social podem evitar obter esse tipo de formação e procurar outros cursos de graduação.

Diante da fala de Miranda et al. (2013) de que a profissão contábil tem baixa valorização quando comparada a carreiras mais tradicionais, há a possibilidade de que esse cenário decorra da falta de conhecimento sobre a profissão. Por isso, é importante que desde o momento da escolha do curso, o indivíduo, ao concluir o Ensino Médio, tenha conhecimentos sobre os cursos, inclusive o de Contabilidade, a fim de que opte por uma graduação em conformidade com seu perfil e gostos pessoais.

Diante do cenário retratado, este estudo se propõe a responder à seguinte questão: qual a percepção de estudantes e egressos do Ensino Médio com relação ao Curso de Ciências Contábeis sob a ótica de estereótipos relacionados à profissão? Consequentemente, o objetivo desta pesquisa consiste em conhecer e analisar as percepções de estudantes e egressos do Ensino Médio com relação ao Curso de Ciências Contábeis, sob a ótica de estereótipos relacionados à profissão.

A contabilidade evoluiu ao longo de sua história, porém os estereótipos-muitos ligados a questões do passado-podem ainda ser atribuídos ao Contador e à profissão contábil. Isso faz com que sejam necessárias pesquisas empíricas que verifiquem se, no cenário atual, tais estereótipos se mantêm condizentes com a literatura. Este estudo visa contribuir para a discussão apresentada, na medida em que se pretende verificar se os resultados encontrados na amostra irão ratificar os achados empíricos já evidenciados em pesquisas anteriores, ou se as respostas serão condizentes com os estereótipos mencionados na literatura. Ressaltase que, embora pesquisas pregressas tenham sido realizadas a respeito do tema, o assunto não se esgotou, tendo em vista a possibilidade de se verificarem realidades distintas em diferentes municípios do Brasil e a necessidade de se compararem os achados de estudos realizados nessas localidades. Este estudo, por exemplo, além de considerar estudantes do Município de Lagoa Santa, MG, visa analisar uma amostra específica de indivíduos: aqueles que frequentaram o evento Mostra de Profissões da Universidade Federal de Minas Gerais (UFMG), recentemente reformulado e agora denominado Mostra Sua UFMG.

$\grave{A}$ vista disso, espera-se que os resultados mapeados possam servir como base para que as escolas de Ensino Médio e as instituições de Ensino Superior promovam ações para a orientação dos estudantes a respeito das profissões disponíveis, inclusive sobre a carreira contábil. Nesse processo, é importante que os alunos, prestes a escolherem a carreira que desejam seguir, tenham conhecimentos realísticos sobre as profissões, a fim de realizarem 
uma escolha adequada ao seu perfil. Esse conhecimento também é relevante para que o estudante permaneça no curso escolhido, uma vez que teve, previamente, um conhecimento coerente e concatenado sobre a carreira selecionada.

\section{REFERENCIAL TEÓRICO}

\subsection{ESTEREÓTIPOS E A CONTABILIDADE}

Conforme já mencionado, o Dicionário Priberam da Língua Portuguesa (2013) define que o estereótipo é uma ideia ou conceito formado antecipadamente ou sem fundamento real e adaptação à situação presente. Os estereótipos podem carregar uma carga negativa de juízo de valor sem embasamento robusto. Para Splitter e Borba (2014), "os estereótipos surgem do processo cognitivo de formar percepções sobre grupos de pessoas, normalmente envolvendo a atribuição de rótulos para esses grupos. Esses rótulos são chamados estereótipos" (p. 128).

Segundo Baccega (1998), o processo de estereotipagem começa com a comunicação. Ainda de acordo com a autora supracitada, quando o homem aprende a falar, ele também aprende a pensar e passa a se relacionar com o mundo, principalmente por meio de palavras, as quais transportam conceitos e estereótipos. Não há distinção precisa entre o significado das palavras conceito e estereótipo, exceto pelo fato de que o estereótipo carrega consigo aspectos valorativos, de juízos de valor, com suas bases emocionais. Baccega (1998) afirma que os estereótipos prejudicam a percepção da realidade, visto que se passa a vê-la de um modo pré-construído pela cultura e transmitido pela linguagem.

O ser humano, ao procurar conhecer a realidade, busca as informações mais acessíveis, isto é, colhe aspectos já recortados e moldados pela cultura, assim, o processo de estereotipia se apodera da vida mental (Bosi, 1992). O indivíduo economiza tempo ao aceitar as ideias pré-concebidas pela sociedade em detrimento da procura pela compreensão dos fatos por meio da busca de dados, análise e raciocínio sobre as informações. Para Baccega (1998), esse processo de facilitação resulta em simplificações excessivas da complexidade dos fatos e acontecimentos sociais.

Para que haja desconstrução dos estereótipos, é necessário criar possibilidades para a correção dessas percepções iniciais inadequadas. E, para Azevedo e Cornachione (2012), "quando os estereótipos inibem a capacidade da profissão de representar fielmente os seus membros e de atrair novos estudantes, torna-se necessário entendê-los e combatê-los" ( $p$. 22). Ao contrário disso, os estereótipos perdurarão, passando de geração para geração. 
Com relação especificamente à profissão contábil, foco deste estudo, um dos estereótipos relacionados a ela é a figura do "bean counter"-termo em inglês utilizado para descrever o "contador de feijão". Esse é um estereótipo negativo que descreve um profissional metódico, conservador, quantitativo e, sobretudo, chato. Além disso, é um profissional que não tem entendimento ou sensação do negócio e desenvolve processos mecânicos e distantes da realidade que sufocam a iniciativa e, possivelmente, levam a organização a tomar decisões prejudiciais a ela (Vaivio \& Kokko, 2006).

Granlund e Lukka (1997) complementam que o "bean counter" é um tipo de pessoa que tende a escrever a história financeira de maneira precisa e correta, ou seja, com exatidão. Ele responde às necessidades da informação formal, mas com relação à comunicação pessoal ou exterior à organização ele é geralmente limitado, prevalecendo a comunicação por intermédio dos relatórios financeiros. No estudo de Splitter e Borba (2014), verificou-se que a amostra de estudantes analisada percebia o Curso de Ciências Contábeis como chato, complexo e que envolve muito a Matemática, ainda havendo, no cenário contemporâneo, a presença do estereótipo do "bean counter".

Miranda et al. (2013) também apontam os estereótipos da profissão contábil, dos quais: ela desenvolve um trabalho enfadonho e sem muitas variações de atividades; há baixo fator salarial; e foco na Matemática e cálculo de impostos. lucídibus e Marion (2002) ressaltam ainda que, em alguns segmentos da economia, principalmente na pequena empresa, a função do Contador foi distorcida, estando voltada quase exclusivamente para o atendimento às exigências do fisco. Tal percepção foi também observada no estudo de Galvão (2016), em que os estudantes investigados percebiam o profissional contábil como aquele capaz de ajudar o governo a aplicar bem os impostos.

Esses estereótipos contribuem para a formação da opinião de que a Contabilidade é uma Ciência Exata. Diante disso, um estudante que não gosta de Matemática, por exemplo, não escolheria a Contabilidade como carreira. Coutinho e Silva e Silva (2012) reiteram que as percepções acerca da precisão e rigor na profissão contábil desanimam estudantes criativos a se tornarem Contadores.

Outros estudos apontam para o estereótipo relacionado ao gênero, em que o Contador é percebido como uma pessoa do sexo masculino (Azevedo, 2010; Leal et al., 2014), e à ética duvidosa do contador (Azevedo \& Cornachione, 2012; Coutinho e Silva \& Silva, 2012; Mbawuni, 2015; Miranda et al., 2013). Coutinho e Silva e Silva (2012) mencionam que a causa da imagem negativa da profissão contábil advém de fatores como estereótipos negativos, escândalos corporativos, falta de informação sobre a importância do papel do Contador perante a sociedade e metodologia de ensino dos cursos de graduação. Esses fatores, conforme salientam os autores supracitados, trazem consequências como a falta de credibilidade nos profissionais e a redução do número de estudantes interessados em se tornarem Contadores. Vicente e Machado (2010) também afirmam que os indivíduos 
geralmente escolhem a sua carreira seguindo o estereótipo que possuem das pessoas de cada profissão.

\subsection{ESTUDOS ANTERIORES}

Há estudos acerca das percepções sobre a profissão contábil tanto no contexto nacional quanto no âmbito internacional. No cenário nacional, podem-se citar os trabalhos de Azevedo (2010), Azevedo e Cornachione (2012), Coutinho e Silva e Silva (2012), Galvão (2016), Leal et al. (2014), Miranda e Faria (2016), Miranda et al. (2013), Moura, Pereira, Miranda, e Medeiros (2016), Rebellato et al. (2017), Silva (2018) e Splitter e Borba (2014). Em âmbito internacional, elencam-se os trabalhos de Cernusca e Balaciu (2015), Granlund e Lukka (1997), Mbawuni (2015), Vaivio e Kokko (2006) e Wells (2015).

Os trabalhos elencados, realizados em diferentes contextos e regiões, mostram que há estereótipos sobre a profissão contábil que ainda prevalecem em algumas regiões, conforme evidenciados na Tabela 1. Por outro lado, há estudos que apontam que, embora ainda haja estereótipos, muitos já não existem, assinalando uma mudança nas percepções, em geral, de maneira positiva.

Tabela 1

Resumo dos principais resultados encontrados

\begin{tabular}{|c|c|}
\hline AUTOR(ES) & ESTEREÓTIPO \\
\hline Granlund e Lukka (1997) & "Bean conter". \\
\hline Vaivio e Kokko (2006) & Não encontrado. \\
\hline Azevedo (2010) & Estereótipo de gênero masculino. \\
\hline $\begin{array}{l}\text { Azevedo e Cornachione } \\
(2012)\end{array}$ & Contabilidade é uma Ciência Exata. \\
\hline $\begin{array}{l}\text { Coutinho e Silva e Silva } \\
(2012)\end{array}$ & Não encontrado. \\
\hline Miranda et al. (2013) & $\begin{array}{l}\text { A Contabilidade é uma Ciência Exata; o Contador tem melhores oportunidades de } \\
\text { trabalho como despachante; a principal atividade é fazer o imposto de renda. }\end{array}$ \\
\hline Splitter e Borba (2014) & $\begin{array}{l}\text { Profissional sem visão de negócios, pouco participativo ou envolvido na gestão; } \\
\text { pouco atualizado; usa muito a lógica e se esquece das pessoas; apenas cumpre } \\
\text { normas; resolve questões operacionais. Quanto à profissão em si, é percebida } \\
\text { envolvendo cálculos e Matemática; ligada a aspectos fiscais e tributários, principal- } \\
\text { mente à declaração do imposto de renda. }\end{array}$ \\
\hline Leal et al. (2014) & Estereótipo de gênero masculino. \\
\hline Mbawuni (2015) & Não encontrado. \\
\hline $\begin{array}{l}\text { Cernusca e Balaciu } \\
(2015)\end{array}$ & Não encontrado. \\
\hline Wells (2015) & Não encontrado. \\
\hline Moura et al. (2016) & $\begin{array}{l}\text { Profissional retratado em filmes como frio, submisso, antissocial, desagradável, } \\
\text { chato, obsessivo, vilão e metódico. }\end{array}$ \\
\hline Miranda e Faria (2016) & Ética duvidosa. \\
\hline
\end{tabular}




\begin{tabular}{ll}
\hline \multicolumn{1}{c}{ AUTOR(ES) } & \multicolumn{1}{c}{ ESTEREÓTIPO } \\
\hline Galvão (2016) & $\begin{array}{l}\text { Contador vinculado principalmente a atividades como cálculos de impostos e decla- } \\
\text { ração do imposto de renda. }\end{array}$ \\
\hline Rebellato et al. (2017) & $\begin{array}{l}\text { Imagem do profissional contemporâneo vinculada à do Contador tradicional, foca- } \\
\text { do na manutenção de registros, que resolve questões burocráticas e operacionais. }\end{array}$ \\
\hline & $\begin{array}{l}\text { A percepção com relação à mulher Contadora mudou, especialmente quanto a es- } \\
\text { tereótipos negativos (de mal-humorada, imaginativa, submissa, melhor preparada } \\
\text { para atividades repetitivas, antissocial para assumindo características de liderança, } \\
\text { realista, sociável, íntegra e honesta). Porém, ainda parece haver, principalmente na } \\
\text { percepção das próprias mulheres, dificuldades que as impedem de se destacarem } \\
\text { no ambiente corporativo. }\end{array}$ \\
\hline
\end{tabular}

\section{METODOLOGIA}

\subsection{CARACTERIZAÇÃO DA PESOUISA E DELIMITAÇÃO DA AMOSTRA}

Com relação aos objetivos, esta pesquisa é caracterizada como descritiva, tendo em vista que visa descrever as características de determinada população ou fenômeno (Gil, 2002). Quanto aos procedimentos, trata-se de um estudo de levantamento ou survey, realizado mediante a aplicação de um questionário. No que diz respeito à abordagem do problema, este estudo pode ser definido como quantitativo.

A amostra selecionada para esta pesquisa consistiu em estudantes e egressos do Ensino Médio residentes no Município de Belo Horizonte e região metropolitana. A seleção da amostra ocorreu em razão de critérios de acessibilidade, portanto, trata-se de uma amostragem não probabilística e os achados não são informações generalizáveis para toda a população de estudantes e egressos do Ensino Médio no Brasil.

A escolha desse público foi porque esses estudantes estão em fase de escolha da carreira que desejam cursar. Espera-se, portanto, explorar o tema da pesquisa com relação a esse público, pois se entende que a escolha da carreira a ser seguida por um indivíduo é pautada, entre diversos motivos, pelos seus gostos pessoais e percepções quanto ao curso escolhido.

\subsection{COLETA DE DADOS}

Para a obtenção dos dados, aplicou-se um questionário aos estudantes e egressos componentes da amostra em versão impressa e on-line. A versão impressa foi aplicada no evento Mostra de Profissões/Mostra Sua UFMG, que ocorreu em setembro de 2016 na Universidade Federal de Minas Gerais e em um cursinho preparatório de vestibular localizado 
no Município de Lagoa Santa, região metropolitana de Belo Horizonte, Minas Gerais. A versão on-line do questionário foi disponibilizada na plataforma Google Drive, durante os meses de setembro a outubro de 2016 e divulgada para os contatos dos pesquisadores, sendo solicitado a eles que encaminhassem para colegas que estivessem cursando ou recémformados no Ensino Médio. Em ambas as versões, somaram-se 143 respondentes.

Destaca-se que o pré-teste do instrumento de pesquisa foi aplicado para os estudantes do cursinho preparatório de vestibular localizado no Município de Lagoa Santa, em agosto de 2016. Como não foram constatadas dúvidas a respeito das questões colocadas, as respostas foram incorporadas aos dados para análise. Também é importante mencionar que, para a coleta dos dados no evento Mostra de Profissões/Mostra Sua UFMG, optou-se por aplicar os questionários em stands de diferentes cursos que faziam parte do evento em questão, todos da Universidade Federal de Minas Gerais (UFMG), para que os resultados não fossem viesados.

O instrumento de pesquisa, adaptado do estudo de Miranda et al. (2013), dispôs inicialmente de questões sobre o perfil do respondente, incluindo informações sobre gênero, idade, estado civil, escolaridade e rede de ensino. Também foram relacionadas questões para identificar o quanto o estudante (ou egresso) conhece sobre o Curso de Ciências Contábeis e sobre a intenção de ingressar em um curso superior. Na sequência, disponibilizou-se um conjunto de 31 questões fechadas agrupadas em quatro categorias: percepções sobre o Curso de Ciências Contábeis, com 10 assertivas; percepções sobre o mercado de trabalho para o Contador, com 13 assertivas; percepções sobre a ética na profissão contábil, com 4 assertivas; e percepções sobre a valorização da profissão contábil, com 4 assertivas.

As questões foram formuladas com base em uma escala tipo Likert, na qual os indivíduos respondem sobre o nível de concordância a respeito das assertivas propostas. Optou-se por colocar um ponto intermediário, a fim de possibilitar que o estudante fosse neutro com relação à assertiva ou não soubesse opinar. Neste estudo, as questões consistiram em afirmações acompanhadas de 5 (cinco) pontos: opções de 1 (um) a 5 (cinco) sobre o nível de concordância, sendo 1 (um)-discordo totalmente; 2 (dois)-discordo; 3 (três)-neutro; 4 (quatro)-concordo e 5 (cinco)-concordo totalmente. Dessa forma, para efeito de análise, respostas menores do que 3 (três) foram consideradas como "discordância" e respostas maiores do que 3 (três) foram consideradas como "concordância" e, por sua vez, respostas iguais a 3 (três) foram consideradas "sem opinião", a fim de identificar o respondente que, possivelmente, não tenha conhecimento ou não queira opinar a respeito da assertiva.

Após a coleta dos dados, estes foram analisados, fazendo-se o uso de tabelas e análises de frequência. Para fins de análise, no que se refere às questões nas quais foram disponibilizadas a escala tipo Likert com 5 (cinco) pontos, vale ressaltar que foram realizados os procedimentos elencados na Tabela 2: 
Tabela 2

Procedimentos de análise da escala tipo Likert

\begin{tabular}{ll}
\hline \multicolumn{1}{c}{ Respostas } & \multicolumn{1}{c}{ Procedimento realizado } \\
\hline $\begin{array}{l}\text { Pontuação } 1 \text { (um) ou } 2 \text { (dois) na } \\
\text { escala }\end{array}$ & $\begin{array}{l}\text { Soma dos percentuais dessas respostas para obter o percentual total } \\
\text { de "discordância" a respeito da assertiva. }\end{array}$ \\
\hline $\begin{array}{l}\text { Pontuação } 4 \text { (quatro) ou } 5 \text { (cinco) na } \\
\text { escala }\end{array}$ & $\begin{array}{l}\text { Soma dos percentuais dessas respostas para obter o percentual total } \\
\text { de "concordância" a respeito da assertiva. }\end{array}$ \\
\hline
\end{tabular}

\section{ANÁLISE DOS RESULTADOS}

\subsection{PERFIL DOS RESPONDENTES}

A primeira parte do questionário foi composta por questões que buscaram traçar o perfil dos respondentes. De modo geral, observou-se que a maior parte dos respondentes possui entre 17 e 18 anos de idade, representado $44,8 \%$ e $21 \%$, respectivamente, sobre o total. As respostas sobre a escolaridade também evidenciam que a maioria dos respondentes está no $2^{\circ}(14,7 \%)$ ou $3^{\circ}$ ano do Ensino Médio $(59,4 \%)$, sugerindo que a grade curricular desses estudantes está regular de acordo com a faixa etária.

Com relação ao gênero, o público feminino foi superior ao masculino, englobando $59,4 \%$ dos respondentes contra $40,6 \%$ do gênero masculino. Quanto ao estado civil, $97,2 \%$ se declararam solteiros. Ademais, a maior parte dos respondentes $(76,2 \%)$ estudam no período matutino.

No que se refere ao exercício de atividade remunerada, nota-se que aproximadamente $74 \%$ dos respondentes não trabalham, contra $25 \%$ que exercem atividade remunerada. A maioria dos indivíduos pesquisados estuda em escola pública (71,3\%), acessa a internet três dias ou mais por semana ( $93 \%$ ) e tal acesso é realizado, predominantemente, em residência própria (90\%).

Com relação ao desejo de cursar uma graduação, obteve-se que apenas $2,1 \%$ não têm interesse em se inserir no Ensino Superior e 4,9\% ainda estão com dúvidas. Ressalta-se que $32,9 \%$ dos estudantes componentes da amostra têm orientação vocacional na escola e esse pode ser um fator motivacional para o interesse do estudante em ingressar no Ensino Superior. Tal orientação é importante, pois contribui para a disseminação do conhecimento sobre cada profissão no mercado de trabalho e para que o indivíduo realize a escolha de acordo com seus gostos pessoais e perfil.

Quanto aos municípios de origem dos estudantes, a maior parte deles concentrou-se no Município de Lagoa Santa (19,6\%). Esse maior percentual ocorreu em razão de o préteste do questionário ter sido realizado nessa localidade, com estudantes de um cursinho pré- 
vestibular. Os Municípios de Brumadinho, Lagoa da Prata, Oliveira e Sete Lagoas também se destacaram.

Entre as graduações que os respondentes pretendem cursar, as mais mencionadas foram: Medicina, Direito, Psicologia, Engenharia, Administração e Fisioterapia, nessa ordem, respectivamente, exceto Administração e Fisioterapia, que obtiveram a mesma frequência de escolha. Destaca-se que 9,1\% dos respondentes têm dúvidas entre dois ou três cursos, com destaque para Direito, Medicina e Psicologia.

Ao serem questionados sobre a principal fonte de informação para a escolha do curso, os respondentes mencionaram que a informação vem, predominantemente, da família $(24,5 \%)$, seguida dos amigos (14\%). No que diz respeito à principal influência na escolha do curso, mais da metade dos respondentes $(66,4 \%)$ disseram que a escolha é pautada no gosto pessoal. Já $18,2 \%$ responderam que o mercado de trabalho é o principal balizador da escolha.

\subsection{QUESTÕES ACERCA DA PROFISSÃO CONTÁBIL}

Tratadas as questões de cunho geral, foram realizados questionamentos acerca da profissão contábil, detalhados na Tabela 3 :

Tabela 3

Percepções iniciais sobre a carreira contábil

\begin{tabular}{|c|c|c|c|}
\hline & & Freq. & $\%$ \\
\hline \multirow{4}{*}{$\begin{array}{l}\text { Conhece alguém que estuda ou trabalha na área con- } \\
\text { tábil? }\end{array}$} & Sim & 72 & 50,3 \\
\hline & Não & 70 & 49 \\
\hline & Não respondeu & 1 & 0,7 \\
\hline & Total & 143 & 100 \\
\hline \multirow{5}{*}{$\begin{array}{l}\text { Qual o seu nível de conhecimento sobre o Curso de } \\
\text { Ciências Contábeis? }\end{array}$} & Muito & 2 & 1,4 \\
\hline & Pouco & 53 & 37,1 \\
\hline & Razoável & 43 & 30,1 \\
\hline & Nenhum & 45 & 31,5 \\
\hline & Total & 143 & 100 \\
\hline \multirow{5}{*}{$\begin{array}{l}\text { Considera a Contabilidade como uma possível carreira } \\
\text { para você? }\end{array}$} & Sim & 18 & 12,6 \\
\hline & Não & 85 & 59,4 \\
\hline & Talvez & 36 & 25,2 \\
\hline & Não respondeu & 4 & 2,8 \\
\hline & Total & 143 & 100 \\
\hline
\end{tabular}




\begin{tabular}{|c|c|c|c|}
\hline & & Freq. & $\%$ \\
\hline \multirow{10}{*}{ Origem do conhecimento da profissão } & Origem & Freq. & $\%$ \\
\hline & Família & 27 & 18,9 \\
\hline & Amigos & 34 & 23,8 \\
\hline & Professor & 19 & 13,3 \\
\hline & Internet & 34 & 23,8 \\
\hline & Jornais e revistas & 8 & 5,6 \\
\hline & Duas opções ou mais & 3 & 2,1 \\
\hline & Outros & 11 & 7,7 \\
\hline & Não responderam & 7 & 4,9 \\
\hline & Total & 143 & 100 \\
\hline
\end{tabular}

Nesse aspecto, destaca-se que $50,3 \%$ dos respondentes conhecem alguém que estuda ou trabalha na área contábil. Isso sugere que aproximadamente a metade dos estudantes e egressos está mais hábil a responder com fidedignidade sobre suas percepções a respeito do Curso. Ao serem questionados sobre o quanto acham que conhecem sobre o Curso de Ciências Contábeis, apenas 1,4\% responderam que conhecem muito, e 37,1\%, 30,1\% e 31,5\%, respectivamente, têm pouco, razoável ou nenhum conhecimento sobre a Graduação em análise, respectivamente.

No que se refere a considerar a Contabilidade como uma possível carreira a ser seguida, mais da metade dos respondentes $(59,4 \%)$ respondeu negativamente a tal possibilidade, contra 25,2\% que não a descartam. Quanto à origem do conhecimento acerca da profissão, as principais respostas foram: os amigos (23,8\%), a internet $(23,8 \%)$, a família $(18,9 \%)$ e o professor $(13,3)$.

\subsection{PERCEPÇÕES ACERCA DO CURSO DE CIÊNCIAS CONTÁBEIS}

Após a identificação do perfil dos estudantes e egressos componentes da amostra, foi proposta a eles uma série de assertivas, a fim de obter a percepção dos respondentes acerca do Curso de Ciências Contábeis. Para facilitar a compreensão, a tabulação dos dados foi realizada em termos percentuais.

O primeiro grupo de assertivas elencadas diz respeito às percepções sobre o Curso de Ciências Contábeis, segundo evidenciado na Tabela 4 : 


\begin{tabular}{|c|c|c|c|c|c|c|}
\hline \multirow[b]{2}{*}{ Questões } & \multicolumn{6}{|c|}{ Frequência (\%) } \\
\hline & DF & $D$ & $\mathrm{~N}$ & C & CF & $\begin{array}{l}\text { Não } \\
\text { resp. }\end{array}$ \\
\hline $\begin{array}{l}\text { 1. O Curso de Ciências Contábeis nas Universidades Públicas é muito } \\
\text { concorrido. }\end{array}$ & 5,6 & 14,7 & 55,9 & 15,4 & 6,3 & 2,1 \\
\hline $\begin{array}{l}\text { 2. No Curso de Ciências Contábeis, o estudante terá muitos componen- } \\
\text { tes curriculares envolvendo Matemática. }\end{array}$ & 2,8 & 4,2 & 15,4 & 28,0 & 45,5 & 4,2 \\
\hline $\begin{array}{l}\text { 3. Para estudar Ciências Contábeis, o estudante precisará de muitos } \\
\text { conhecimentos em Informática. }\end{array}$ & 4,2 & 9,8 & 35,0 & 34,3 & 11,9 & 4,9 \\
\hline 4. Para estudar Ciências Contábeis, é necessário ler muito. & 5,6 & 14,0 & 30,8 & 20,3 & 24,5 & 4,9 \\
\hline $\begin{array}{l}\text { 5. Para a formação do Contador, há necessidade de matérias de Ciên- } \\
\text { cias Humanas (do tipo Sociologia, Filosofia, Psicologia). }\end{array}$ & 14,7 & 25,2 & 23,1 & 19,6 & 14,0 & 3,5 \\
\hline $\begin{array}{l}\text { 6. Para a formação do Contador, há necessidade de matérias na área } \\
\text { de Direito. }\end{array}$ & 9,8 & 17,5 & 25,9 & 21,7 & 21,0 & 4,2 \\
\hline $\begin{array}{l}\text { 7. As aulas do Curso de Ciências Contábeis são mais práticas que } \\
\text { teóricas. }\end{array}$ & 12,6 & 24,5 & 32,2 & 14,7 & 10,5 & 5,6 \\
\hline $\begin{array}{l}\text { 8. O Curso de Ciências Contábeis forma profissionais capazes de } \\
\text { tomar decisões. }\end{array}$ & 4,9 & 6,3 & 21,0 & 32,2 & 33,6 & 2,1 \\
\hline 9. Contabilidade não se aprende na faculdade, mas, sim, na prática. & 23,1 & 16,1 & 23,8 & 18,9 & 14,7 & 3,5 \\
\hline $\begin{array}{l}\text { 10. O Curso de Ciências Contábeis "tem cara" de curso feito para } \\
\text { homens. }\end{array}$ & 69,2 & 8,4 & 9,1 & 4,9 & 6,3 & 2,1 \\
\hline
\end{tabular}

De acordo com as respostas obtidas, é possível observar que a maioria dos respondentes não tem opinião formada a respeito da concorrência do Curso de Ciências Contábeis nas universidades públicas, uma vez que a maior parcela das respostas foi de cunho neutro.

Um percentual elevado dos estudantes e egressos acredita que há muitos componentes curriculares envolvendo a Matemática (45,5\% dos respondentes concordam fortemente com a afirmativa e $28 \%$ concordam com ela). Esse percentual geral de concordância $(73,5 \%)$ corrobora os estudos realizados por Azevedo e Cornachione (2012), Miranda et al. (2013) e Splitter e Borba (2014), sendo que, neste último, os autores constataram um percentual de 91,5\% de estudantes que concordaram que envolveria muito a Matemática em um Curso de Contabilidade, reforçando o estereótipo de que a Contabilidade é uma Ciência Exata. Tal estereótipo pode inibir indivíduos que não gostam de Matemática a escolherem o Curso, mesmo que eles possuam as habilidades e capacidades exigidas pela profissão.

Uma parcela considerável dos respondentes $(46,2 \%)$ concordou sobre a necessidade de conhecimentos de Informática no Curso, enquanto outros $35 \%$ não têm opinião formada a respeito do assunto. Importante mencionar que matérias como Laboratório Contábil e Sistemas de Informações Contábeis fazem parte da grade curricular do Curso de Ciências Contábeis da Universidade Federal de Minas Gerais, e esse é um conteúdo importante para a formação do Contador, visto que o ambiente de trabalho desse profissional é informatizado 
e se utilizam cada vez mais as tecnologias para aprimorar a função. Além disso, o suporte tecnológico é um meio de utilizar menos tempo com tarefas mais operacionais e mais tempo na geração de informações tempestivas para a tomada de decisões.

Quanto à carga de leitura, $44,8 \%$ percebem que é preciso muita leitura e, por outro lado, 30,8\% dos respondentes não têm opinião formada sobre o assunto. Esse resultado não confirma o estudo de Splitter e Borba (2014), cujas evidências denotam que o Contador é um profissional pouco atualizado, apenas evidencia o desconhecimento de parte dos estudantes quanto à necessidade de leitura para o Curso.

Ademais, cerca de $40 \%$ dos respondentes entendem que matérias da área de Humanas não se fazem necessárias para a formação do Contador e 33,6\% têm opinião contrária. Salienta-se que, embora não haja componentes curriculares como Sociologia, Filosofia e Psicologia no Curso de Ciências Contábeis da UFMG, algumas matérias trazem em seu conteúdo aspectos relacionados a tais componentes curriculares e são imprescindíveis para o processo de aprendizagem, pois exigem do futuro Contador uma avaliação compreensiva dos fatos históricos, das relações sociais, das dinâmicas interpessoais, além de uma reflexão crítica a respeito de cada um desses fenômenos.

No que se refere às matérias da área do Direito, $42,7 \%$ dos respondentes concordaram que essas são primordiais para a formação do Contador, considerando que este deve atender a uma ampla gama de normas jurídicas para o exercício de sua profissão; esse conteúdo é necessário e está relacionado à assertiva número 4 (quatro), que diz que o estudante de Ciências Contábeis precisa ler muito, pois as normas são atualizadas constantemente. Componentes curriculares como Direito Privado, Direito Tributário e Legislação Social fazem parte da grade curricular do Curso de Ciências Contábeis da UFMG.

De acordo com Miranda et al. (2013), é corrente em cursos da área de Humanas maior carga de conteúdos teóricos. Sendo a Ciência Contábil uma Ciência Social, a assertiva 7 buscou verificar se, na percepção dos respondentes, as aulas ministradas no Curso de Ciências Contábeis são mais práticas do que teóricas. Observou-se 37,1\% de discordância, enquanto $32,2 \%$ das respostas foram neutras. Esse resultado permite inferir que uma parte considerável dos respondentes tem ciência sobre a necessidade de componentes curriculares teóricos. Porém, o desconhecimento é predominante na amostra estudada.

A afirmativa 8 questionou se o Curso de Ciências Contábeis forma profissionais capazes de tomar decisões. Verificou-se que $33,6 \%$ dos respondentes concordaram fortemente com a assertiva, ao passo que $32,2 \%$ concordaram, totalizando um nível de concordância de $65,8 \%$. Esses resultados evidenciam que mais da metade dos respondentes têm consciência a respeito de matérias de cunho gerencial no Curso de Contabilidade. Tal evidência se opõe aos achados de Vaivio e Kokko (2006), que apontam o estereótipo do "bean counter" e de Splitter e Borba (2014), que mencionam a crença de que o Contador é um profissional que 
não tem visão de negócios. Assim, tais resultados podem representar uma transição positiva nas percepções sobre o Contador.

É importante reafirmar que, de acordo com o International Federation of Accountants (IFAC, 2016), as habilidades organizacionais e de gerenciamento de negócios são relevantes para o Contador e se relacionam às habilidades de trabalhar com e dentro da organização, de modo a propiciar melhores resultados das pessoas e dos recursos disponíveis, como liderança, capacidade de influenciar outras pessoas, direcionando-as para os objetivos da organização, aplicação de ferramentas apropriadas e tecnologias que melhoram a eficiência e eficácia da organização, bem como a tomada de decisões.

Por fim, a última assertiva desta seção buscou identificar se os estudantes e egressos percebem o Curso de Ciências Contábeis como uma graduação feita para pessoas do gênero masculino. Como resultado, 6,3\% dos respondentes concordaram fortemente e 4,9\% concordaram que esse é um curso para homens. Ressalta-se que, na amostra analisada, o estereótipo de gênero masculino na Contabilidade não prevalece em sua maioria, isto posto, esses resultados não corroboram aqueles apontados por Azevedo (2010) e Leal et al. (2014).

\subsection{PERCEPÇÕES SOBRE O MERCADO DE TRABALHO PARA O CONTADOR}

$\mathrm{Na}$ Tabela 5, sumarizam-se os resultados encontrados a respeito da percepção dos respondentes sobre o mercado de trabalho para o Contador:

Tabela 5

Percepções sobre o mercado de trabalho para o Contador

\begin{tabular}{|c|c|c|c|c|c|c|}
\hline \multirow[b]{2}{*}{ Questões } & \multicolumn{6}{|c|}{ Frequência (\%) } \\
\hline & DF & D & $\mathrm{N}$ & $\mathrm{C}$ & CF & $\begin{array}{l}\text { Não } \\
\text { resp. }\end{array}$ \\
\hline 11. O Contador pode abrir um escritório de Contabilidade. & 2,8 & 2,8 & 11,9 & 19,6 & 60,1 & 2,8 \\
\hline $\begin{array}{l}\text { 12. O Contador tem como atividade principal calcular o imposto de } \\
\text { renda. }\end{array}$ & 4,9 & 21,7 & 25,2 & 26,6 & 16,8 & 4,9 \\
\hline $\begin{array}{l}\text { 13. É um profissional que auxilia as pequenas empresas a não "que- } \\
\text { brarem, irem à falência". }\end{array}$ & 2,1 & 11,9 & 24,5 & 26,6 & 29,4 & 5,6 \\
\hline $\begin{array}{l}\text { 14. O Contador encontra várias oportunidades de trabalho por } \\
\text { meio da realização de concursos públicos. }\end{array}$ & 2,8 & 8,4 & 38,5 & 21 & 25,2 & 4,2 \\
\hline $\begin{array}{l}\text { 15. O Contador tem oportunidades de emprego em atividades rela- } \\
\text { cionadas ao meio ambiente. }\end{array}$ & 25,2 & 23,8 & 23,1 & 16,1 & 7,7 & 4,2 \\
\hline $\begin{array}{l}\text { 16. O Contador encontra as melhores oportunidades de trabalho } \\
\text { como despachante. }\end{array}$ & 21,7 & 25,9 & 28,7 & 17,5 & 2,8 & 3,5 \\
\hline $\begin{array}{l}\text { 17. Teve suas oportunidades de emprego ampliadas com o cresci- } \\
\text { mento das ONGs. }\end{array}$ & 8,4 & 29,4 & 24,5 & 23,8 & 7,4 & 6,3 \\
\hline 18. O Contador tem capacidade de dirigir uma empresa. & 1,4 & 9,8 & 18,9 & 30,8 & 35,7 & 3,5 \\
\hline
\end{tabular}




\begin{tabular}{|c|c|c|c|c|c|c|}
\hline \multirow[b]{2}{*}{ Questões } & \multicolumn{6}{|c|}{ Frequência (\%) } \\
\hline & DF & D & $\mathrm{N}$ & C & CF & $\begin{array}{l}\text { Não } \\
\text { resp. }\end{array}$ \\
\hline $\begin{array}{l}\text { 19. Quem fez o Curso de Técnico em Contabilidade, pode fazer o } \\
\text { mesmo trabalho do Contador com curso superior. }\end{array}$ & 14,0 & 19,6 & 25,2 & 18,2 & 19,6 & 3,5 \\
\hline 20. O Contador como profissional, de maneira geral, ganha pouco. & 14,7 & 16,8 & 38,5 & 16,8 & 8,4 & 4,9 \\
\hline 21. Encontra empregos facilmente em grandes empresas. & 7,0 & 18,9 & 33,6 & 20,3 & 16,8 & 3,5 \\
\hline $\begin{array}{l}\text { 22. O Curso de Ciências Contábeis forma profissionais que encon- } \\
\text { tram boas oportunidades de emprego. }\end{array}$ & 0,7 & 11,2 & 31,5 & 31,5 & 21,7 & 3,5 \\
\hline $\begin{array}{l}\text { 23. O Contador tem menores oportunidades de trabalho do que } \\
\text { quem cursa Administração. }\end{array}$ & 20,3 & 22,4 & 28,0 & 16,8 & 8,4 & 4,2 \\
\hline
\end{tabular}

A partir das respostas obtidas, verifica-se que $60,1 \%$ dos respondentes concordam fortemente que o Contador pode abrir um escritório de Contabilidade e 19,6\% concordam com a assertiva. Quando questionados se a principal tarefa do Contador seria calcular o imposto de renda, considerando uma análise agregada, 43,4\% dos estudantes e egressos concordaram com a afirmativa. Esse resultado traz indícios de que, na percepção dos respondentes, o trabalho do Contador é mais voltado ao cálculo de impostos, conforme assinalam os achados de Splitter e Borba (2014) e os apontamentos na literatura de Miranda et al. (2013).

Com relação à assertiva, 13,56\% concordaram que o Contador auxilia a pequena empresa a não falir. A fragilidade desse tipo de empresa, associada à falta de informações contábil-financeiras em seu processo de decisão, faz com que ela tenda a apresentar uma situação de maior risco diante da concorrência, o que remete à necessidade de um controle mais eficaz que permita decisões mais estruturadas, de forma a conduzir à obtenção de melhores resultados (Moreira, Encarnação, Bispo, Colauto, \& Angotti, 2013). Nesse cenário, a Contabilidade possui o papel de gerar informações ao empresário de modo a favorecer tomadas de decisões mais acertadas e em tempo hábil (Atkinson, Kaplan, \& Matsumura, 2000). O resultado apresentado na afirmativa 13 confirma aquele obtido na assertiva 8 (o Curso de Ciências Contábeis forma profissionais capazes de tomar decisões), já que a continuidade de uma empresa está relacionada às decisões de seus gestores e essas definem os rumos da entidade.

A respeito da oportunidade de trabalho por meio de concurso público, um percentual considerável de estudantes $(38,5 \%)$ não soube opinar a respeito da assertiva, enquanto $46,2 \%$ concordaram ou concordaram fortemente que essa é uma oportunidade de trabalho para o Contador. Tendo em vista que o objeto da Contabilidade é o controle do patrimônio, a gestão pública também necessita do trabalho exercido pelo Contador e, a partir dos resultados encontrados, pode-se inferir que quase a metade dos respondentes desconhece o objeto da Contabilidade. 
Quanto às atividades relacionadas ao meio ambiente, aproximadamente $50 \%$ dos estudantes discordaram ou discordaram fortemente sobre a possibilidade de o Contador exercer algum trabalho relacionado ao meio ambiente, enquanto $23,8 \%$ dos respondentes concordaram com a assertiva. Esse resultado permite verificar desconhecimento sobre a Contabilidade Ambiental. Importante destacar que a Contabilidade Ambiental é um dos componentes curriculares lecionados no Curso de Ciências Contábeis da UFMG e esse é um ramo da Contabilidade indispensável, uma vez que as empresas, para produzirem, consomem recursos e, entre eles, os naturais. $O$ consumo desses recursos é restrito em razão da necessidade de preservação do meio ambiente. Portanto, existe a legislação ambiental que as empresas devem observar e o Contador necessita estar atento a tal norma.

Questionou-se, também, se o Contador encontra as melhores oportunidades de trabalho como despachante: $47,6 \%$ dos respondentes discordaram da assertiva, já os outros $28,7 \%$ não têm opinião formada a respeito do assunto. Cabe destacar que o papel primordial do Contador é subsidiar as organizações, municiando-as de informações úteis para a tomada de decisões e não o de prestar serviços como despachantes contábeis. Isso, por sua vez, seria uma aproximação do estereótipo do "bean counter", mencionado por Granlund e Lukka (1997) e por Vaivio e Kokko (2006), ao relatarem a execução de processos mecânicos.

Com relação à assertiva 17, verificou-se que, na percepção dos estudantes, os Contadores não tiveram mais oportunidades de emprego com o crescimento das Organizações Não Governamentais (ONGs), tendo em vista que $37,8 \%$ dos respondentes discordaram ou discordaram fortemente da assertiva. De acordo com Miranda et al. (2013), na realidade, a necessidade de transparência cada vez maior nessas organizações ampliou as oportunidades de trabalho para o Contador.

No que se refere à capacidade de o Contador dirigir uma empresa, cumulativamente, $66,4 \%$ dos estudantes concordaram com a afirmativa. Observa-se, nesse resultado, uma quebra do estereótipo de que o Contador é um mero calculador de impostos e sem habilidades de gestão, como apontado por Granlund e Lukka (1997), Vaivio e Kokko (2006) e Splitter e Borba (2014), embora na assertiva $1243,4 \%$ dos respondentes tenham assinalado o cálculo de impostos como uma das principais atividades do Contador.

Quanto à assertiva 19 (Quem fez o Curso de Técnico em Contabilidade, pode fazer - mesmo trabalho do Contador com curso superior), 25,2\% dos estudantes e egressos não opinaram a respeito, mas uma parcela considerável $(37,8 \%)$ entende que o Técnico em Contabilidade pode fazer o mesmo trabalho do Contador. De acordo com o Conselho Federal de Contabilidade (CFC, 2019), há atribuições que são prerrogativas exclusivas do Contador Bacharel em Ciências Contábeis. O artigo 25, alínea c do Decreto-Lei 9.295 de 1946 informa, por exemplo, algumas dessas funções: "perícias judiciais ou extrajudiciais, revisão de balanços e de contas em geral, verificação de haveres revisão permanente ou periódica de escritas, regulações judiciais ou extrajudiciais de avarias grossas ou comuns, assistência 
aos Conselhos Fiscais das sociedades anônimas [...]". Desse modo, tal percepção por parte dos respondentes de que o Técnico em Contabilidade poderá exercer as mesmas funções do Contador sugere uma desvalorização da formação de nível superior em Ciências Contábeis.

Quando se questionou a respeito da remuneração do Contador (assertiva 20), 31,5\% discordaram que este é um profissional que, de maneira geral, ganha pouco, enquanto $25,2 \%$ consideram que o Contador tem baixa remuneração. Miranda et al. (2013) ressaltam que, em vista do crescimento da oferta de Cursos de Ciências Contábeis, a oferta de profissionais também cresceu, fazendo com que houvesse redução da faixa salarial. O percentual de discordância (31,5\%) dessa assertiva é similar àquele encontrado por esses autores $(34,3 \%)$ na amostra estudada por eles.

A assertiva 21 buscou verificar se, na percepção dos respondentes, o Contador encontra emprego com facilidade em grandes empresas, de modo que $37,1 \%$ deles concordaram com a afirmativa. Já com relação às oportunidades de emprego (assertiva 22), mais da metade dos estudantes e egressos entendem que o Contador tem boas oportunidades de emprego e, ao comparar essas oportunidades com a carreira de Administrador, 42,7\% discordaram que o Contador tem menos oportunidades de trabalho do que o Administrador. Percepção similar foi verificada no estudo de Splitter e Borba (2014), em que os respondentes opinaram que - Curso em análise oferece muitas possibilidades de empregabilidade, embora com fator salarial menor do que outras profissões.

\subsection{PERCEPÇÕES SOBRE A ÉTICA NA PROFISSÃO CONTÁBIL}

Com relação às percepções dos respondentes sobre a ética na profissão contábil, os resultados dos questionamentos encontram-se detalhados na Tabela 6:

\begin{tabular}{|c|c|c|c|c|c|c|}
\hline \multirow[b]{2}{*}{ Questões } & \multicolumn{6}{|c|}{ Frequência (\%) } \\
\hline & DF & D & $\mathrm{N}$ & $\mathrm{C}$ & CF & $\begin{array}{l}\text { Não } \\
\text { resp. }\end{array}$ \\
\hline $\begin{array}{l}\text { 24. Em sua atuação profissional, o Contador favorece apenas os pa- } \\
\text { trões. }\end{array}$ & 37,8 & 25,2 & 16,8 & 6,99 & 9,79 & 3,5 \\
\hline $\begin{array}{l}\text { 25. O Contador tem a ética como uma qualidade sempre presente em } \\
\text { seu trabalho. }\end{array}$ & 4,9 & 15,4 & 25,2 & 20,3 & 30,8 & 3,5 \\
\hline $\begin{array}{l}\text { 26. É o profissional que dá "jeitinhos" e tem honestidade sempre duvi- } \\
\text { dosa. }\end{array}$ & 35,0 & 17,5 & 24,5 & 13,3 & 5,6 & 4,2 \\
\hline 27. Possui padrões éticos inferiores aos de outras profissões. & 43,3 & 11,9 & 21,7 & 9,8 & 8,4 & 4,9 \\
\hline
\end{tabular}

A terceira categoria de assertivas buscou identificar a percepção dos respondentes acerca da ética na profissão contábil. A primeira delas verificou se, na opinião dos estudantes 
e egressos, o Contador favorece apenas os patrões em sua atuação profissional. Os resultados mostram, em sua maioria, que os respondentes discordam dessa afirmativa (63\%), ou são neutros quanto ao assunto. Porém, identifica-se que aproximadamente $16 \%$ concordaram com a afirmativa em análise. É importante observar que, se o Contador favorece apenas - patrão, o empregado é o desfavorecido na relação trabalhista e o profissional não trabalharia de forma independente, seguindo as leis e padrões de ética profissional. Nota-se que houve uma quebra do estereótipo de que o Contador é antiético, conforme apresentado na literatura (Azevedo \& Cornachione, 2012; Coutinho e Silva \& Silva, 2012; Mbawuni, 2015; Miranda et al., 2013; Moura et al., 2016).

Com relação à assertiva 25 ( $O$ Contador tem a ética como uma qualidade sempre presente em seu trabalho), os resultados apontam que $30,8 \%$ dos respondentes concordam fortemente com a assertiva, enquanto $20,3 \%$ concordam. Os estudantes e egressos, ao serem questionados se o Contador é o profissional que dá "jeitinhos" e tem honestidade duvidosa, em sua maioria, discordaram da afirmativa (52,5\%). Esse resultado confirma aqueles obtidos na assertiva 24 (Em sua atuação profissional, o Contador favorece apenas os patrões); sinaliza que os estudantes e egressos do Ensino Médio analisados não veem o Contador como um profissional antiético e reforça o rompimento do estereótipo quanto a essa característica (Azevedo \& Cornachione 2012; Coutinho e Silva \& Silva, 2012; Mbawuni, 2015; Miranda et al., 2013; Moura et al., 2016).

A última assertiva desse grupo de questões buscou comparar a ética na profissão contábil com esse mesmo comportamento em outras profissões. Como resultado, obteve-se que a maioria $(55,2 \%)$ discorda que a profissão contábil tenha padrões éticos inferiores a outras profissões. Esses resultados também são corroborados por aqueles encontrados nas assertivas 24, 25 e 26. Miranda et al. (2013) explicitam que a Contabilidade teve sua visão rebaixada em razão de aspectos relacionados à desonestidade de empresários, cujas ações antiéticas foram descobertas e que usaram profissionais contábeis para realizá-las, tanto contadores quanto auditores, a exemplo do caso empírico ocorrido na empresa Enron. Conforme os dados coletados a partir desta pesquisa, verifica-se que, ao menos na amostra analisada, não houve percepção negativa com relação à ética do profissional contábil.

\subsection{PERCEPÇÕES SOBRE A VALORIZAÇÃO DA PROFISSÃO CONTÁBIL}

No último grupo de questões elencadas no instrumento de pesquisa, foram relacionadas afirmativas sobre a valorização da profissão contábil (Tabela 7): 
Tabela 7

Percepções sobre a valorização da profissão contábil

\begin{tabular}{|c|c|c|c|c|c|c|}
\hline \multirow[b]{2}{*}{ Questões } & \multicolumn{6}{|c|}{ Frequência (\%) } \\
\hline & DF & D & $\mathrm{N}$ & C & CF & $\begin{array}{l}\text { Não } \\
\text { resp. }\end{array}$ \\
\hline $\begin{array}{l}\text { 28. A profissão de Contador tem destaque em nossa sociedade, assim } \\
\text { como o Direito e a Medicina. }\end{array}$ & 29,4 & 18,9 & 28 & 9,1 & 11,2 & 3,5 \\
\hline $\begin{array}{l}\text { 29. Minha família aprovaria se eu cursasse Ciências Contábeis em nível } \\
\text { superior. }\end{array}$ & 7,7 & 13,3 & 23,8 & 18,9 & 32,2 & 4,2 \\
\hline $\begin{array}{l}\text { 30. A profissão desenvolve um trabalho enfadonho/rotineiro e sem mui- } \\
\text { tas variações de atividades. }\end{array}$ & 9,8 & 19,6 & 34,3 & 22,4 & 10,5 & 3,5 \\
\hline 31. É uma carreira que oferece grandes oportunidades de crescimento. & 4,2 & 10,5 & 24,5 & 24,5 & 33,6 & 2,8 \\
\hline
\end{tabular}

A primeira assertiva compara o destaque da profissão em comparação a outras, como o Direito e a Medicina. Observa-se que um percentual considerável dos respondentes $(48,3 \%)$ discorda que a profissão contábil tem destaque na sociedade comparada ao Direito e à Medicina. Esse resultado sugere um desprestígio da profissão comparada àquelas mais tradicionais. Vale lembrar que esses cursos foram os mais almejados pelos indivíduos componentes da amostra. $O$ estudo de Miranda et al. (2013) também apresentou resultados similares. Ainda, os respondentes foram questionados se a família deles aprovaria, caso decidissem ingressar no Curso de Ciências Contábeis. Nesse contexto, 51,1\% disseram que suas famílias aprovariam a escolha do Curso. Esse resultado sugere que, apesar de existirem outras profissões que seriam preferidas se comparadas à carreira contábil, esta última não é mal vista pelos estudantes e egressos e seus familiares.

Abordou-se, também, sobre a rotina de trabalho do Contador. O objetivo foi verificar se os respondentes a percebem como uma rotina enfadonha e sem muitas variações de atividades. Como resultado, 32,9\% concordaram que o trabalho é rotineiro, enquanto $34,3 \%$ foram neutros quanto à afirmativa. Esse resultado mostra desconhecimento sobre a rotina do Contador e corrobora os achados de Miranda et al. (2013) de que as funções desse profissional seriam enfadonhas e sem muitas variações de atividades.

A última assertiva desse grupo buscou avaliar a percepção dos estudantes e egressos sob a perspectiva das oportunidades de crescimento oferecidas pela carreira. Destaca-se que mais de $50 \%$ dos respondentes concordaram que a Contabilidade é uma carreira que oferece grandes oportunidades de crescimento, embora apenas $37,8 \%$ considerem a Contabilidade como uma possível carreira a ser seguida. Esse resultado é relevante, pois evidencia que o trabalho do Contador é valorizado ao oferecer oportunidades de crescimento na carreira. 


\section{CONSIDERAÇÕES FINAIS}

O objetivo deste estudo foi conhecer e analisar as percepções de estudantes e egressos do Ensino Médio com relação ao Curso de Ciências Contábeis, sob a ótica de estereótipos relacionados à profissão. Buscou-se avaliar se os indivíduos componentes da amostra conheciam o Curso de Ciências Contábeis, quais as suas percepções a respeito da profissão contábil, especificamente sobre assuntos relacionados ao mercado de trabalho, ética e valorização da profissão, além de analisar se os resultados da pesquisa corroborariam ou não os estereótipos apontados na literatura contábil.

Os resultados encontrados mostram que, na amostra estudada, a maioria dos estudantes e egressos possui algum conhecimento sobre o Curso, como a necessidade de leitura, informática, conteúdos teóricos, vínculo à área do Direito e conteúdos gerenciais. Porém, entendem que componentes curriculares relacionados às Ciências Humanas são desnecessários no Curso e que há demasiado conteúdo matemático.

No que se refere à profissão, observou-se que há desconhecimento da possibilidade de atuação do Contador em áreas como a ambiental e em ONGs. Por outro lado, os respondentes reconhecem que o Contador pode exercer cargos gerenciais, auxiliar na continuidade das empresas, possui oportunidades de carreira na esfera pública, além da possibilidade de abrir escritórios e conseguir oportunidades em grandes empresas. Os estudantes e egressos também entendem que a profissão contábil é uma carreira que oferece grandes oportunidades de crescimento e que teriam aprovação da família caso viessem a escolher a Graduação em análise. No entanto, ao comparar a profissão com o Direito e a Medicina, a Contabilidade tem menor prestígio.

Este estudo evidencia, portanto, que há estereótipos sobre a profissão contábil que ainda prevalecem, como a percepção de que a Contabilidade é uma Ciência Exata, que envolve muito a Matemática. Tal percepção pode afastar estudantes que tenham dificuldades nessa área específica da escolha pelo Curso de Ciências Contábeis, mesmo que esses indivíduos, na realidade, representassem excelentes profissionais contábeis.

Por outro lado, os achados sugerem que embora ainda haja estereótipos, muitos já inexistem, assinalando uma mudança, de maneira positiva, nas percepções dos estudantes. Por exemplo, embora grande parte dos respondentes assumam que o Contador tem como atividade principal calcular o imposto de renda, eles também consideram que o profissional contábil auxilia as empresas no processo de tomada de decisão. Ou seja, embora em segundo plano, já existe a visão da função gerencial da Contabilidade. Além disso, os respondentes não percebem o Contador como um profissional antiético, culminando no fato de que, embora uma série de escândalos contábeis tenham sido evidenciados na mídia nos últimos anos, isso não repercutiu na visão geral de que todos os Contadores seriam antiéticos. Tal situação 
denota a capacidade de os respondentes não se aterem a casos isolados e transformarem tais casos em um reflexo da profissão.

Ressalta-se, diante do exposto, a necessidade de as instituições que oferecem o Ensino Médio fornecerem informações adequadas a respeito das carreiras pretendidas pelos alunos, bem como estimularem a participação desses últimos em eventos como a Mostra de Profissões realizada pela UFMG. Isso faria com que os estudantes escolhessem os cursos de graduação baseados em informações mais acertadas, o que poderia, em última instância, reduzir os níveis de evasão no Ensino Superior quando a desistência estivesse associada a uma escolha inadequada do curso.

Este estudo apresenta algumas limitações que podem ser destacadas. A amostra selecionada se refere a estudantes e egressos do Ensino Médio residentes no Município de Belo Horizonte e região metropolitana, sendo que poderia abranger outras regiões. $O$ fato de a amostra ser não probabilística limita a possibilidade de realizar inferências sobre a população a partir da análise das respostas obtidas. A técnica de coleta de dados por meio de questionários também pode apresentar problemas, como a dependência de respostas de autorrelato, de modo que os respondentes nem sempre preenchem os instrumentos de pesquisa de forma que melhor mostre a realidade. Por fim, as conclusões obtidas nesta pesquisa foram elaboradas com base na predominância das respostas. Porém, houve elevados percentuais de respostas neutras na escala tipo Likert, evidenciando um possível desconhecimento dos respondentes a respeito das proposições realizadas e dificultando a realização de inferências.

Sugere-se a realização de trabalhos futuros que possam verificar se há diferenças em termos de conhecimentos sobre o Curso de Ciências Contábeis em escolas públicas ou privadas. Atenta-se, ainda, para maiores incentivos a eventos que apresentem a esse público os diversos cursos de graduação existentes no País.

\section{REFERÊNCIAS}

Atkinson, A. A., Kaplan, R. S., \& Matsumura, E. M. (2000). Contabilidade gerencial. São Paulo: Atlas.

Azevedo, R. F. L. (2010). A percepção pública sobre os contadores: Bem ou mal na foto? (Dissertação de mestrado). Universidade de São Paulo, São Paulo.

Azevedo, R. F. L., \& Cornachione, E. B., Jr. (2012, janeiro/março). Ética profissional contábil: Uma análise visual da percepção pública. Revista de Educação e Pesquisa em Contabilidade (REPeC), 6(1), 19-37. doi:10.17524/repec.v6il.237 
Baccega, M. A. (1998, setembro/dezembro). O estereótipo e as diversidades. Comunicação \& Educação, 5(13), 7-14. doi:10.11606/issn.2316-9125.v0i13p7-14

Bosi, E. (1992, março). Entre a opinião e o estereótipo. Novos Estudos CEBRAP, São Paulo, $32,111-118$.

Cernusca, L., \& Balaciu, D. E. (2015). The perception of the accounting students on the image of the accountant and the accounting profession. Journal of Economics and Business Research, 21(1), 7-24.

Conselho Federal de Contabilidade. (2019). Prerrogativas de Contadores e Técnicos em Contabilidade. Recuperado de https://cfc.org.br/

Coutinho e Silva, A. H., \& Silva, E. G. R. da (2012). Percepção dos Estudantes de Ciências Contábeis do Rio de Janeiro sobre o estereótipo do profissional de Contabilidade no período após a adoção do IFRS. Anais do Congresso Nacional de Administração e Ciências Contábeis-AdCont, Rio de Janeiro, 3.

Decreto-Lei 9.295 (1946).

Dicionário Priberam da Língua Portuguesa. (2013). Estereótipo. Recuperado de http://www. priberam.pt/dlpo/estere\%c3\%b3tipo

FGV On-line. (2019). Recuperado de https://www.google.com/url?sa $=t \& r c t=j \& q=\delta$ esrc $=s \&$ source $=$ web\&cd $=1 \&$ ved $=2$ ahUKEwjDkO2i6NXIAhW8GLkGHZ6rCx4QFjAAegQ|Ax$\mathrm{AC} \& u r l=h t t p \% 3 \mathrm{~A} \% 2 \mathrm{~F} \% 2 \mathrm{Fead} 2$.fgv.br\%2FIs5\%2Fcentro_rec\%2Fdocs\%2Fo_caso_enron_ papel_auditorias.doc\&usg=AOvVaw2ND8qyKg2+FKPiTjoS9TnL

Galvão, N. M. S, (2016). Percepção dos Estudantes do Ensino Médio Acerca do Profissional Contábil. Revista Evidenciação Contábil \& Finanças, 4(2), 40-53. doi:10.18405/recfin20160203

Gil, A. C. (2002). Como elaborar projetos de pesquisa. (4ª ed.). São Paulo: Atlas.

Granlund, M., \& Lukka, K. (1997). From bean-counters to change agents: the Finnish management accounting culture in transition. The Finnish Journal of Business Economics, 1(3), 213-255.

International Federation of Accountants. (2016). Handbook of International Education Pronouncements 2015 Edition. Recuperado de http://www.ifac.org 
lucídibus, S., \& Marion, J. C. (2002). Introdução à Teoria da Contabilidade. (6 $6^{a}$ ed.). São Paulo: Atlas.

Leal, E. A., Miranda, G. J., Araújo, T. S., \& Borges, L. F. M. (2014, janeiro/abril). Estereótipos na Profissão Contábil: A opinião de estudantes e do público externo no Triângulo Mineiro. Contabilidade, Gestão e Governança, 17(1), 134-153, jan./abr.

Mbawuni, J. (2015). Examining Students' Feelings and Perceptions of Accounting Profession in a Developing Country: The Role of Gender and Student Category. International Education Studies, 8(6), 9-23.

Miranda, C. S., Miranda, R. A. de M., \& Araujo, A. M. P. (2013, janeiro/abril). Percepções dos Estudantes do Ensino Médio sobre o Curso de Ciências Contábeis e as Atividades do Profissional Contador. Revista de Gestão, Finanças e Contabilidade, 3(1), 17-35. doi:10.18028/rgfc.v3il.105

Miranda, V. de L., \& Faria, J. A. de. (2016). Caricaturas e Estereótipos do Contador: Como a imagem do profissional de contabilidade vem sendo veiculada em um jornal de grande circulação no Brasil? RACE, Revista de Administração, Contabilidade e Economia, 15(3), 1087-1116. doi:10.18593/race.v15i3.9807

Moreira, R. L., Encarnação, L. V., Bispo, O. N. A., Colauto, R. D., \& Angotti, M. (2013). A importância da informação contábil no processo de tomada de decisão nas micro e pequenas empresas. Revista Contemporânea de Contabilidade, 10(19), 119-140. doi:10.5007/2175-8069.2013v10n19p119

Moura, M. F., Pereira, N. A., Miranda, G. J., \& Medeiros, C. R. O. (2016). Herói ou Vilão? Mudanças no Estereótipo dos Contadores na Produção Cinematográfica. Revista de Auditoria Governança e Contabilidade, 4(14), 129-147.

Rebellato, C. A., Nascimento, S., \& Rodniski, C. M. (2017). Percepção dos Discentes e Docentes Acerca do Estereótipo da Profissão Contábil. Anais do Seminário de Iniciação Científica, Seminário Integrado de Ensino, Pesquisa e Extensão e Mostra Universitária, Joaçaba, 1.

Silva, C. A. T. (2007). Contabilidade. Florianópolis: UFSC.

Silva, D. J. M. (2018). Mulheres na contabilidade: Os estereótipos socialmente construídos sobre a contadora (Dissertação de mestrado). Universidade Federal de Uberlândia, Uberlândia. 
Splitter, K., \& Borba, J. A. (2014, abril/junho). Percepção de estudantes e professores universitários sobre a profissão do contador: Um estudo baseado na teoria dos Estereótipos. Revista de Educação e Pesquisa em Contabilidade (REPeC), 8(2), 126-141. doi:10.17524/ repec.v8i2.1027.

Vaivio, J., \& Kokko, T. (2006). Counting Big: Re-examining the Concept of the Bean Counter Controller. The Finnish Journal of Business Economics, 10(1), 49-74.

Vicente, C. C. da S., \& Machado, M. J. (2010). A imagem dos contabilistas: Diferenças e factores que as determinam. Anais da Conferência: Innovación y responsabilidad: Desafios y soluciones. Coimbra, Portugal, 1.

Wells, P. K. (2015). New Zealand high school students' perception of accounting: How and why those perceptions were formed. Accounting Education, 24(6), 461-479.

\section{Como citar este artigo:}

ABNT

ALMEIDA, Jucellia Paulista de; AVELINO, Bruna Camargos; BRUGNI, Talles Vianna. Percepções de estudantes e egressos do Ensino Médio sobre o Curso de Ciências Contábeis: uma análise sob a ótica dos estereótipos da profissão. RACE, Revista de Administração, Contabilidade e Economia, Joaçaba: Editora Unoesc, v. 19, n. 1, p. 127-152, jan./abr. 2020. Disponível em: http://editora.unoesc.edu.br/index.php/race. Acesso em: dia/mês/ano.

\section{APA}

Almeida, J. P. de, Avelino, B. C., \& Brugni, T. V. (2020). Percepções de estudantes e egressos do Ensino Médio sobre o Curso de Ciências Contábeis: Uma análise sob a ótica dos estereótipos da profissão. RACE, Revista de Administração, Contabilidade e Economia, 19(1), 127-152. Recuperado de http://editora.unoesc.edu.br/index.php/race 
